Check for updates

Cite this: RSC Adv., 2017, 7, 48754

Received 21st September 2017

Accepted 9th October 2017

DOI: $10.1039 / \mathrm{c} 7 \mathrm{ra10483a}$

rsc.li/rsc-advances

\section{Total synthesis and structural revision of a mangrove alkaloid $\uparrow$}

\author{
Michael T. Green, (D) $\ddagger^{\mathrm{a}}$ Gary R. Peczkowski,,$^{\mathrm{b}}$ Aneesa J. Al-Ani, ${ }^{\mathrm{a}}$ \\ Sophie L. Benjamin, (D) ${ }^{c}$ Nigel S. Simpkins (D) $^{\text {b }}$ and Alan M. Jones (D) *d
}

We report the total synthesis of an alkaloid isolated from the mangrove fungi Hypocrea virens, based on the originally claimed structure, via a photochemical sequence. Inconsistencies between data sets led to a revision of the proposed structure followed by a concise synthetic sequence to deliver the revised natural product.
Natural products have served as the source or architectural inspiration for countless drug discovery efforts. In the field of oncology for instance, around half of all final drug entities were either natural products or directly derived from them during the past 70 years. ${ }^{1}$ This could be due to their pre-validated biological relevance and coverage of different regions of chemical space. ${ }^{2}$ More recently, natural products from the marine world have been subject to extensive exploration and yielded compounds that have become clinically approved therapeutics such as ziconotide and trabectedin. ${ }^{3}$ Marine derived fungal metabolites have become an important new avenue of research in identifying novel structures with potential bioactivity from spores and cultures.

Connected to our other efforts in medicinal chemistry we became interested in exploring novel nitrogen based heterocycles as new scaffolds. ${ }^{4}$ Recently, the isolation and spectral<smiles>CN1C(=O)c2cc3ccccc3c(=O)n2C1=O</smiles>

1<smiles>O=C1NC(=O)n2c1cc1ccc(Oc3ccccc3)cc1c2=O</smiles>

2
Fig. 1 Reported structure of natural product 1 and a related bioactive analogue 2 .

${ }^{a}$ Division of Chemistry and Environmental Science, Manchester Metropolitan University, $M 15 G D$, UK

${ }^{b}$ School of Chemistry, University of Birmingham, Edgbaston, B15 2TT, UK

${ }^{c}$ School of Science and Technology, Nottingham Trent University, NG11 8NS, UK

${ }^{d}$ School of Pharmacy, University of Birmingham, Edgbaston, B15 2TT, UK. E-mail: a.m. jones.2@bham.ac.uk; Tel: +44(0)1214-147288

$\dagger$ Electronic supplementary information (ESI) available. CCDC 1569814, 1569815, 1569797. For ESI and crystallographic data in CIF or other electronic format see DOI: $10.1039 / \mathrm{c} 7 \mathrm{ra} 10483 \mathrm{a}$

\$ M. T. G and G. R. P contributed equally to this work. characterisation of the first naturally occurring example of an imidazo[1,5- $b]$ isoquinoline-1,3,5(2H)-trione alkaloid (1, Fig. 1) from the mangrove fungus, Hypocrea virens has been reported by Hua and co-workers. ${ }^{5}$ Subsequently, Davies and co-workers have reported a single example of the related, 7-phenoxyimidazo[1,5- $b]$ isoquinoline-1,3,5(2H)-trione skeleton (2, Fig. 1) that exhibits sub-micromolar potency for inhibition of the proto-oncogene serine/threonine-protein kinase, PIM1 $\left(\mathrm{IC}_{50}=\right.$ $804 \mathrm{nM} \pm 37 \mathrm{nM})^{6}$
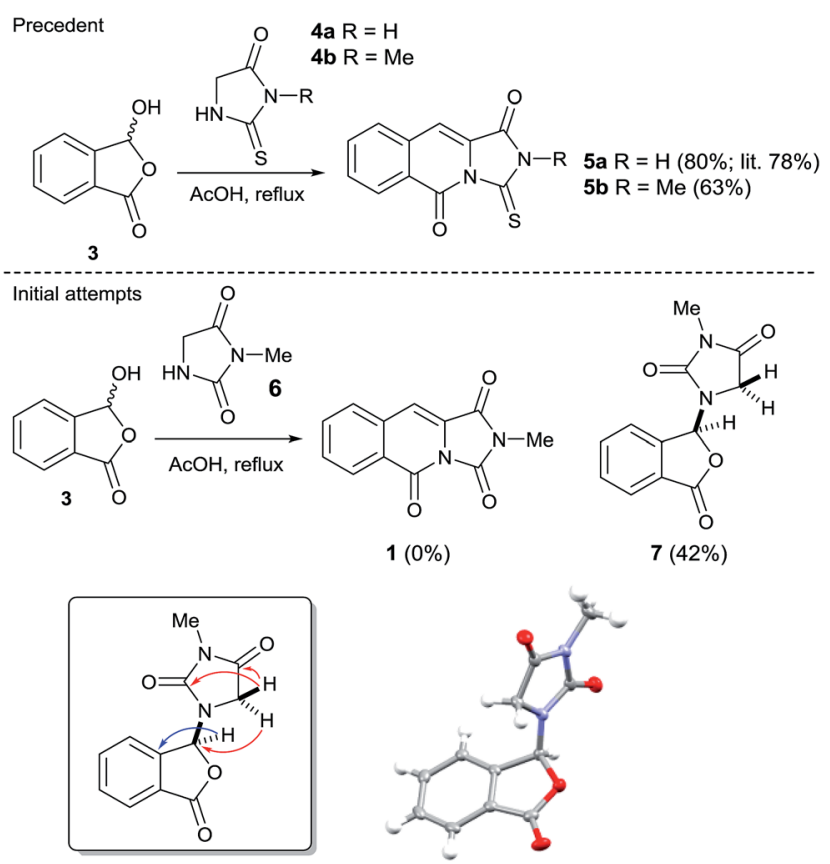

Scheme 1 Literature precedent for the reaction of a thiohydantoin with 2-carboxybenzaldehyde to afford the tricyclic scaffold; result of the analogous hydantoin and 2-carboxybenzaldehyde experiment and inset selected instructive ${ }^{1} \mathrm{H}-{ }^{13} \mathrm{C}$ HMBC correlations and small molecule X-ray crystal structure of 7 . 


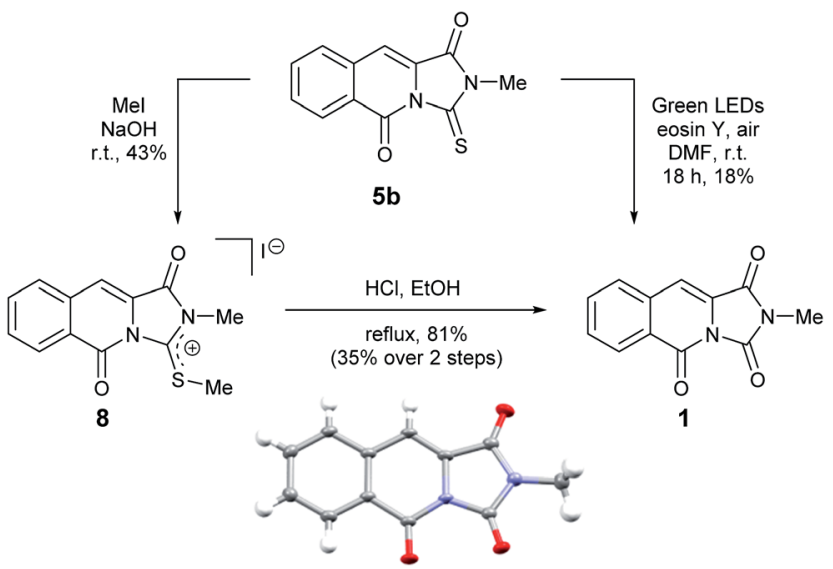

Scheme 2 Two alternative desulfurisation routes to the reported mangrove alkaloid 1 and single crystal X-ray structure of 1 (inset).

Despite the apparent simplicity of $\mathbf{1}$, there have been no confirmatory syntheses reported to date of this mangrove alkaloid. Intrigued by both the structure of $\mathbf{1}$ and the recently reported bioactivity of a related analogue, we pursued a synthetic campaign to alkaloid $\mathbf{1}$.

Our initial approach to 1 envisioned a concise route; a double Knoevenagel and amide bond disconnection to 2-carboxybenzaldehyde 3 and 3-methylimidazolidine-2,4-dione 6 (Scheme 1). 6 in turn, could be prepared via a regioselective N3-alkylation of hydantoin with dimethylacetal dimethylacetamide (DMADMA) in $53 \%$ isolated yield. ${ }^{7}$ The reaction of 2-carboxybenzaldehyde 3 and a related hydantoin analogue, thiohydantoin $\mathbf{4 a}$ has previously been reported to afford the related heterocyclic scaffold $\mathbf{5 a}$ (Scheme 1). ${ }^{\mathbf{8}}$
However, treatment of 6 with 2-carboxybenzaldehyde 3 failed to deliver 1 , instead an isobenzofuranone derivative 7 was afforded in $42 \%$ isolated yield. The connectivity of 7 was unambiguously assigned using a ${ }^{1} \mathrm{H}_{-}{ }^{13} \mathrm{C}$ HMBC experiment (Scheme 1, inset). ${ }^{9}$ Other instructive spectral measurements included the splitting of the methylene signal in the ${ }^{1} \mathrm{H}$ NMR spectrum, indicating diastereotopic protons which was confirmed by ${ }^{1} \mathrm{H}-{ }^{13} \mathrm{C}$ HSQC NMR. ${ }^{9}$ Conclusive evidence for the structure of 7 was obtained by small molecule X-ray crystallography (Scheme 1, inset). ${ }^{\mathbf{1 0}}$ There are limited reports for the preparation of this isobenzofuranone derivative. ${ }^{\mathbf{1 1}}$ In summary, unusual reactivity of hydantoin gave an unexpected reaction product compared to thiohydantoin with 2-carboxybenzaldehyde (Scheme 1). ${ }^{\mathbf{1 2}}$ Attempts to intercept the reaction pathway via a protecting group strategy or sequentially performing the Knoevenagel step and the amide formation were also not successful.

We therefore sought to use the tricyclic manifold of $\mathbf{5 b}$ as a rapid entry to 1 via a desulfurisation approach. Stoichiometric strategies to convert thioamides and thioureas to amides or ureas, respectively are well known. ${ }^{13}$ On simple monofunctionalised thioamides a desulfurisation route using a photo-redox catalyst has been reported. ${ }^{\mathbf{1 4}}$ Employing a photosynthetic route using Eosin-Y and green LEDs enabled the modest preparation of $\mathbf{1}$ but to the best of our knowledge this is the first report in a more complex heterocyclic setting (solvent and UV/vis studies are shown in the ESI). ${ }^{9}$ Alternatively, a twostep methylation and hydrolysis route also delivered $\mathbf{1}$ in an improved yield (Scheme 2).

To our delight, compound 1 crystallised upon standing in $\mathrm{CDCl}_{3}$. Small molecule X-ray crystallography (Scheme 2)

Table 1 Comparison of the NMR spectra of isolated 1 and synthetic 1
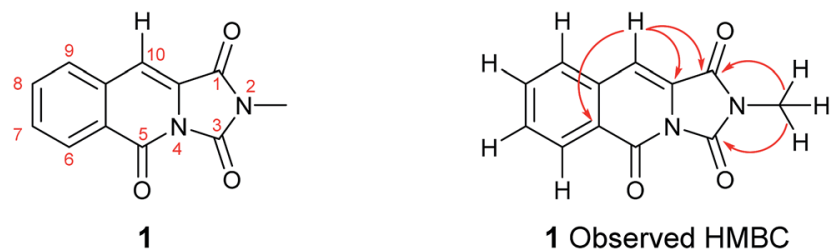

1 Observed HMBC

\begin{tabular}{|c|c|c|c|c|c|c|}
\hline \multicolumn{4}{|c|}{ Isolated material $1\left(\mathrm{CDCl}_{3}\right)$} & \multicolumn{3}{|c|}{ Synthesised material $\mathbf{1}\left(\mathrm{CDCl}_{3}\right)$} \\
\hline No. & $\delta_{\mathrm{H}}(J$ in $\mathrm{Hz})$ & $\delta_{\mathrm{C}}$ & HMBC & $\delta_{\mathrm{H}}(J$ in $\mathrm{Hz})$ & $\delta_{\mathrm{C}}$ & HMBC \\
\hline 1 & & $156.5^{a}$ & & & 159.3 & \\
\hline 3 & & $156.4^{a}$ & & & 149.4 & \\
\hline 5 & & $156.5^{a}$ & & & 156.9 & \\
\hline $5 \mathbf{a}$ & & 136.3 & & & 128.7 & \\
\hline 6 & $8.49, \mathrm{~d}, 1 \mathrm{H}(8.2)$ & 117.2 & C8, C9a & 8.56, d, $1 \mathrm{H}(7.5)$ & 129.3 & $\mathrm{C} 5, \mathrm{C} 8, \mathrm{C} 9 \mathrm{a}$ \\
\hline 7 & $7.63, \mathrm{dd}, 1 \mathrm{H}(8.2,7.4)$ & 130.2 & C9 & 7.69-7.75, m, 2H & 130.4 & C9 \\
\hline 8 & $7.48, \mathrm{dd}, 1 \mathrm{H}(7.6,7.4)$ & 126.9 & C6, C9a & 7.81, ddd, $1 \mathrm{H}(7.5,1.5)$ & 134.1 & C6, C9a \\
\hline 9 & $7.78, \mathrm{~d}, 1 \mathrm{H}(7.6)$ & 124.0 & $\mathrm{C} 5 \mathrm{a}, \mathrm{C7}, \mathrm{C} 10$ & 7.69-7.74, m, 2H & 129.1 & $\mathrm{C} 7$ \\
\hline 9a & & 128.7 & & & 133.7 & \\
\hline 10 & $7.71, \mathrm{~s}, 1 \mathrm{H}$ & 119.6 & C5a, C9a, C10a & $7.36, \mathrm{~s}, 1 \mathrm{H}$ & 109.1 & C1, C5a, C10a \\
\hline $10 a$ & & 126.4 & & & 126.8 & \\
\hline $\mathrm{NCH}_{3}$ & $3.47, \mathrm{~s}, 3 \mathrm{H}$ & 27.6 & $\mathrm{C} 1, \mathrm{C} 3$ & $3.27, \mathrm{~s}, 3 \mathrm{H}$ & 24.7 & $\mathrm{C} 1, \mathrm{C} 3$ \\
\hline
\end{tabular}

${ }^{a}$ These $\delta_{\mathrm{C}}$ values were reported to be interchangeable. ${ }^{5}$ 
<smiles>CN1C(=O)c2cc3ccccc3c(=O)n2C1=O</smiles>

1
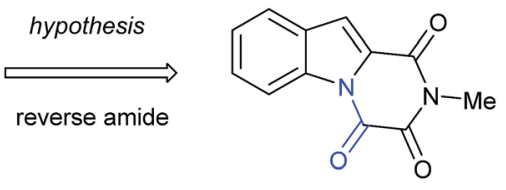

9
Fig. 2 The connectivity pattern of the reported isolated material 1 (shown in black) and the most likely structural isomer 9 .
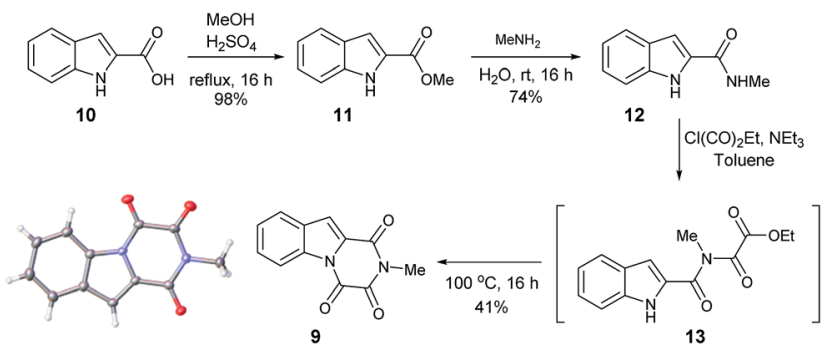

Scheme 3 Synthetic route to the proposed natural product 9 and small molecule $X$-ray crystal structure of 9 (inset).

confirmed the preparation of structure 1. However, comparison of our NMR spectroscopic data with the originally reported ${ }^{5}$ revealed important disparities (Table 1).

It became obvious by comparison of the NMR spectral data that the isolated example of $\mathbf{1}$ differed from that of synthesised 1 (Table 1). In particular, in the ${ }^{1} \mathrm{H}$ NMR spectrum the location of the $\mathrm{C} 10-\mathrm{H}(+0.35 \mathrm{ppm})$ and $N 2$-methyl group $(+0.20 \mathrm{ppm})$ in isolated $1 v s$. synthesised 1, respectively. Intriguingly, in the original report ${ }^{5}$ the amide, urea and arylamide ${ }^{13} \mathrm{C}$ NMR spectral carbonyl shifts were all reported to be within $\pm 0.1 \mathrm{ppm}$, which would be highly unlikely in the claimed structure. ${ }^{15}$ Furthermore, our synthesised example of $\mathbf{1}$ more closely replicates the known ethyl derivative reported by Niopas and Smail, in particular the location of the $\mathrm{C} 10-\mathrm{H} .{ }^{16}$ It was therefore shown by both NMR spectroscopy and confirmation of the small molecule X-ray crystal structure that the previously isolated natural product had different connectivity. Therefore, taking account of all of the above it was proposed that the isolated structure claimed as $\mathbf{1}$, was in actual fact structural isomer $\mathbf{9}$ a metabolite of the gliotoxin family (Fig. 2).

Furthermore, other metabolites isolated from Hypocrea virens and related mangrove fungi include gliotoxin derivatives demonstrating a potential common biosynthetic pathway. ${ }^{17}$ Compound 9 is a natural product recently isolated from the marine fungus Neosartorya pseudofischeri with NMR spectral data reported in $\mathrm{d}_{6}$-DMSO. ${ }^{18}$ In order to compare the spectra of 9 with the isolation data associated with the claimed structure of 1, a total synthesis and NMR spectra measurement in $\mathrm{CDCl}_{3}$ was required (Scheme 3), 9 having previously been prepared only via degradation studies of gliotoxin with selenium. ${ }^{19}$ Furthermore, the proposed structure 9 held promise, as it has also been reported to be found in isolates from Penicillium terlikowskii. ${ }^{20}$

Esterification of indole 2-carboxylic acid $\mathbf{1 0}$ followed by conversion to the $\mathrm{N}$-methyl amide $\mathbf{1 2}$ in water proceeded smoothly. ${ }^{21}$ The conversion of $\mathbf{1 2}$ to $\mathbf{9}$ proved more challenging, with closure of the amine and amide motifs onto a range of reported oxalyl derivatives giving mixed results. ${ }^{22}$ The use of ethyl chlorooxoacetate proved effective via initial formation of 13 (observed in the crude ${ }^{1} \mathrm{H}$ NMR after $1 \mathrm{~h}$ at reflux) to afford 9 in $41 \%$ isolated yield. Comparison of the ${ }^{1} \mathrm{H}$ and ${ }^{13} \mathrm{C}$ NMR spectra in $\mathrm{CDCl}_{3}$ revealed that 9 matched the isolation NMR

Table 2 Comparison of the isolation data for 1 and the revised structure 9 (both in $\left.\mathrm{CDCl}_{3}\right)^{24}$
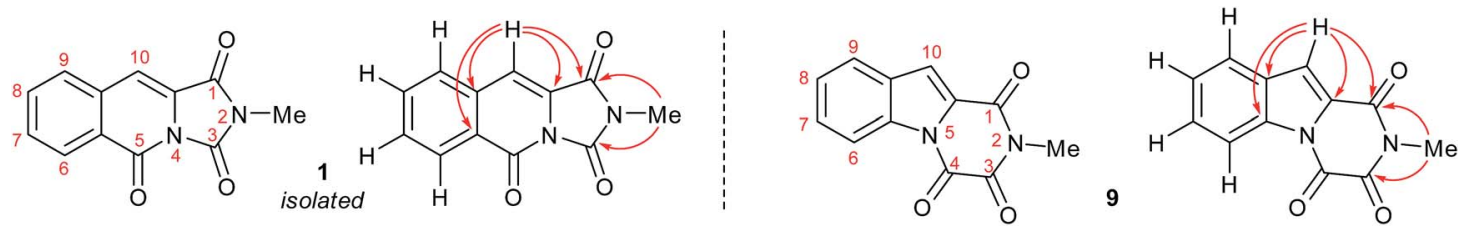

Isolated material $1\left(\mathrm{CDCl}_{3}\right)$

\begin{tabular}{|c|c|c|c|c|c|c|}
\hline 1 & & 156.5 & & & 156.37 & \\
\hline 3 & & 156.4 & & & 156.45 & \\
\hline $5 a$ & & 136.3 & & & 136.3 & \\
\hline 6 & $8.49, \mathrm{~d}, 1 \mathrm{H}(8.2)$ & 117.2 & C8, C9a & $8.47, \mathrm{dq}, 1 \mathrm{H}(8.3,0.9)$ & 117.2 & $\mathrm{C} 8, \mathrm{C} 9 \mathrm{a}$ \\
\hline 7 & $7.63, \mathrm{dd}, 1 \mathrm{H}(8.2,7.4)$ & 130.2 & C9 & 7.62, ddd, $1 \mathrm{H}(8.4,7.3,1.2)$ & 130.2 & C5a, C9 \\
\hline 9a & & 128.7 & & & 128.7 & \\
\hline 10 & $7.71, \mathrm{~s}, 1 \mathrm{H}$ & 119.6 & C5a, C9a, C10a & $7.70, \mathrm{~d}, 1 \mathrm{H}(0.8)$ & 119.6 & C1, C5a, C9a, C10a \\
\hline 10a & & 126.4 & & & 126.4 & \\
\hline $\mathrm{NCH}_{3}$ & $3.47, \mathrm{~s}, 3 \mathrm{H}$ & 27.6 & $\mathrm{C} 1, \mathrm{C} 3$ & $3.47, \mathrm{~s}, 3 \mathrm{H}$ & 27.6 & $\mathrm{C} 1, \mathrm{C} 3$ \\
\hline
\end{tabular}


details for the claimed structure of $\mathbf{1}$ (Table 2) with some subtle differences. The complete structural assignment began from the $\mathrm{C} 6-\mathrm{H}$ due to the effect of being forced into the deshielding cone of the peri-carbonyl group (C4). ${ }^{23}$ The ${ }^{1} \mathrm{H}$ NMR spectral data was in good accordance between synthesised 9 and isolated 1 with $<0.02$ ppm differences for the $\mathrm{C} 6-\mathrm{H}$ and $\mathrm{C} 10-\mathrm{H}$. Due to the pulse sequence used further splitting of the aromatic coupling pattern was observed at the ${ }^{4} J$ level as expected in a planar W-coupling system. The reported and observed ${ }^{1} \mathrm{H}-{ }^{13} \mathrm{C}$ HMBC correlations for $\mathbf{9}$ matched with the isolation data for $\mathbf{1}$ plus due to the strength of our sample further weak, but in agreement, correlations were observed (Table 2). Conclusive evidence for the structure of $\mathbf{9}$ was obtained by the small molecule X-ray crystal structure (Scheme 3 , inset). ${ }^{\mathbf{1 0}}$

In summary, we have shown that the originally isolated natural product $\mathbf{1}$ through synthesis was gliotoxin derivative $\mathbf{9}$. We have reported the first synthesis, combining a photochemical step of the claimed structure of the mangrove alkaloid $\mathbf{1}$ and through structural revision, completed the first total synthesis of the revised natural product 9. The reassignment of the natural product isolated from Hypocrea virens opens the door to elucidating the biosynthesis or shunt metabolism of gliotoxin derivatives and provides a new scaffold to investigate the synthesis of gliotoxin family members. The biological evaluation of the reassigned natural product and related family members will be investigated and reported in due course.

\section{Conflicts of interest}

There are no conflicts to declare.

\section{Acknowledgements}

We acknowledge the EPSRC and AstraZeneca for iCASE support of G. R. P. The NMR instruments used in this research were obtained through Birmingham Science City: Innovative Uses for Advanced Materials in the Modern World (West Midlands Centre for Advanced Materials Project 2), with support from Advantage West Midlands (AWM) and part funded by the European Regional Development Fund (ERDF). The authors thank Dr Phil Craven and Dr Stuart Langley for helpful discussions, MMU for a vacation scholarship to M. T. G. and Dr Louise Male and the Centre for Chemical and Materials Analysis in the School of Chemistry at the University of Birmingham for analytical support. We are indebted to Prof. Hui-Ming Hua (Shenyang Pharmaceutical University, China) for providing the scanned NMR spectra of $\mathbf{1}$ for comparison to our synthesised example and helpful correspondence.

\section{Notes and references}

1 (a) D. J. Newman and G. M. Cragg, J. Nat. Prod., 2007, 70, 461; (b) D. J. Newman and G. M. Cragg, J. Nat. Prod., 2012, 75, 311.

2 S. Wetzel, A. Schuffenhauer, S. Roggo, P. Ertl and H. Waldmann, Chimia, 2007, 61, 355.

3 (a) T. F. Molinski, D. S. Dalisay, S. L. Lievens and J. P. Saludes, Nat. Rev. Drug Discovery, 2009, 8, 69; (b)
R. Montaser and H. Luesch, Future Med. Chem., 2011, 12, 1475; (c) H. Malve, J. Pharm. BioAllied Sci., 2016, 8, 83.

4 A. W. Hensbergen, V. R. Mills, I. Collins and A. M. Jones, Tetrahedron Lett., 2015, 56, 6478.

5 T. Liu, Z.-L. Li, Y. Wang, L. Tian, Y. H. Pei and H.-M. Hua, Nat. Prod. Res., 2011, 25, 1596.

6 C. J. R. Bataille, M. B. Brennan, S. Byrne, S. G. Davies, M. Durbin, O. Fedorov, K. V. M. Huber, A. M. Jones, S. Knapp, G. Liu, A. Nadali, C. E. Quevedo, A. J. Russell, R. G. Walker, R. Westwood and G. M. Wynne, Bioorg. Med. Chem., 2017, 25, 2657.

7 (a) M. J. Porter, N. J. White, G. E. Howells and D. D. P. Laffan, Tetrahedron Lett., 2004, 45, 6541; (b) Y. L. Janin, C. Huel, G. Flad and S. Thirot, Eur. J. Org. Chem., 2002, 1763.

8 A. I. Khodair, J.-P. Gesson and E. H. El-Ashry, Phosphorus, Sulfur Silicon Relat. Elem., 2004, 179, 2653.

9 See ESI. $\dagger$

10 Crystallographic data for compounds 1, 7 and 9 have been deposited with the accession numbers CCDC 1569814, 1569815 and 1569797 contains the supplementary crystallographic data for this paper. $\dagger$

11 (a) M. L. Baron, I. D. Rae and P. M. Simmonds, Aust. J. Chem., 1982, 35, 2567; (b) D. R. Brittain and R. Wood, Imperial Chemical Industries PLC Patent, US4386100 A1, 1983.

12 The differential reactivity of hydantoin $v s$. thiohydantoin with 2-carboxybenzaldehyde was postulated to be due to the greater nucleophilicity of the N1-nitrogen in hydantoin due to increased charge transfer from nitrogen to sulphur in the thiohydantoin structure.

13 (a) A. Corsaro and V. Pistarà, Tetrahedron, 1998, 54, 15027; (b) S. Sahu, P. R. Sahoo, S. Patel and B. K. J. Mishra, J. Sulfur Chem., 2011, 32, 171.

14 A. Yadav, V. Srivastava and L. Yadav, New J. Chem., 2013, 37, 4119.

15 NMR spectroscopic data for 1 was supplied courtesy of Prof. Hui-Ming Hua (Shenyang Pharmaceutical University, China).

16 I. Niopas and G. A. Smail, J. Chem. Soc., Perkin Trans. 1, 1991, 113.

17 (a) A. Marion, M. Groll, D. Scharf, K. Scherlach, M. Glaser, H. Sievers, M. Schuster, C. Hertweck, A. A. Brakhage, I. Antes and E. M. Huber, ACS Chem. Biol., 2017, 12, 1874; (b) T. Amatov and U. Jahn, Angew. Chem., Int. Ed., 2014, 53, 3312 .

18 W.-L. Liang, X. Le, H.-J. Li, X.-L. Yang, J.-X. Chen, J. Xu, H.-L. Liu, L.-Y. Wang, K.-T. Wang, K.-C. Hu, D.-P. Yang and W.-J. Lan, Mar. Drugs, 2014, 12, 5657.

19 (a) J. D. Dutcher, J. R. Johnson and W. F. Bruce, J. Am. Chem. Soc., 1944, 66, 617; (b) J. R. Johnson, R. B. Hasbrouck, J. D. Dutcher and W. F. Bruce, J. Am. Chem. Soc., 1945, 67, 423; (c) M. I. P. Boente, G. W. Kirby, G. L. Patrick and D. J. Robins, J. Chem. Soc., Perkin Trans. 1, 1991, 1283.

20 M. S. Ali, J. S. Shannon and A. Taylor, J. Chem. Soc. C, 1968, 16, 2044.

21 S. N. Mistry, J. Shonberg, C. J. Draper-Joyce, C. K. Herenbrink, M. Michino, L. Shi, A. Cristopoulos, 
B. Capuano, P. J. Scammells and J. R. Lane, J. Med. Chem., 2015, 58, 6819.

22 (a) R. W. Foster, E. N. Lenz, N. S. Simpkins and D. Stead, Chem. -Eur. J., 2017, 23, 8810; (b) M. Rees, N. S. Simpkins and L. Male, Org. Lett., 2017, 19, 1338; (c) A. Cabanillas, C. D. Davies, L. Male and N. S. Simpkins, Chem. Sci., 2015, 6, 1350 .

23 A. M. Jones, T. Lebl, S. Patterson, T. van Mourik, H. A. Früchtl, D. Philp, A. M. Z. Slawin and N. J. Westwood, Tetrahedron, 2009, 65, 563.

24 The provided NMR spectra ${ }^{15}$ for isolated material 1 was found to be inconsistent with the structure of synthesised
1 and consistent with the spectroscopic data for 9. The only difference between synthesised $\mathbf{9}$ and isolated $\mathbf{1}$ was the ${ }^{13} \mathrm{C}$ NMR shifts for the three carbonyl groups. In the original publication $^{5}$ the three carbonyl groups were reported as being interchangeable at 156.4-156.5 ppm in $\mathrm{CDCl}_{3}$. As expected due to the different environments for the three carbonyl groups, three ${ }^{13} \mathrm{C}$ NMR signals are seen in 9 at 156.45, 156.37 and 148.8 ppm. Resonances at 156.5, 156.4 and $148.8 \mathrm{ppm}$ are also seen in the provided scanned ${ }^{13} \mathrm{C}$ NMR spectra of isolated 1 including the previously unassigned carbonyl peak at $148.8 \mathrm{ppm}$. 